\title{
Development of Methods of Analysis of Biological Active Substances for Standardization of Dense Extract of Creeping Thyme
}

\author{
Nadiya Zarivna $1, *$ *i), Liliya Logoyda 1 (D) \\ 1 Department of Pharmaceutical Chemistry, I. Ya. Horbachevsky - Ternopil National Medical University, Ukraine \\ * Correspondence: zarivna@tdmu.edu.ua;
}

Scopus Author ID 57202011083

Received: 1.07.2020; Revised: 14.08.2020; Accepted: 15.08.2020; Published: 19.08.2020

\begin{abstract}
Pharmaceutical development of mucolytic agent with dense extract of creeping thyme and essential oil of thyme involves obtaining a dense thyme extract of creeping, that is, choosing of optimal conditions that will allow in a short time to obtain a dense extract enriched with the main biological active substances (BAS) - which is a resultant extract and finished drug. Since in the analysis of creeping thyme herb in order to standardize this raw material as a quality index, among others, we chose the composition of flavonoids and hydroxycinnamic acids and the quantitative content of flavonoids, then it is appropriate to study the qualitative and quantitative composition of these bioactive substances and in the obtained extract. The aim of our work was to develop methods of analysis of BAS for the standardization of dense extract of creeping thyme; Identification and determination of the quantitative content of the analyzed biological active substances in herbal medicinal products and their respective extracts were carried out using modern sensitive and selective methods of analysis (thin-layer chromatography, differential spectrophotometry); As a result of TLC, the presence of fructose, glucose, arabinose, xylose, and rhamnose were found in the dense creeping thyme extract. According to the ratio of the size and intensity of staining on the chromatograms, it has been concluded that the predominant monosaccharide is fructose, and from the reducing monosaccharides - glucose, which will allow them to choose markers of the quality of the test extract. We also identified tyrosine, alanine, leucine, glycine, glutamic and aspartic acids at the levels of the respective zones on the chromatogram of the comparison solution. Chromatographic studies of a dense extract of creeping thyme by the thin-layer chromatography method have allowed identifying phenol carboxylic acids - rosmarinic (main representative), caffeic and chlorogenic; flavonoids - luteolin-7-O-glucoside, apigenin-7-O-glucoside, luteolin, apigenin, and rutin. Two acids were not identified, small quantities of which are found in the upper part of a chromatogram and of the unidentified structure of luteolin glucoside, which, by size and intensity of fluorescence, are not the main representative of flavonoids in the extract. Based on the literature, this representative of flavonoids may be Luteolin-7-O-di or triglycoside; Qualitative composition of a dense extract of creeping thyme herb in BAS groups - flavonoids, amino acids, polysaccharides has been studied. In order to standardize the extract, identification markers from phenolic compounds - luteolin-7-O-glucoside, luteolin, rutin, chlorogenic, rosmarinic, and caffeic acids, luteolin glycoside of unknown composition has been proposed. The quantitative content of flavonoids, amino acids, and reconstructive monosaccharides in the dense extract has been investigated. The correlation of content of the main BAS groups for dense extract indicates that the selected conditions for transferring the liquid extract to the dense are correct. When standardizing the dense extract of creeping thyme by the flavonoid content is proposed to be at least $2.5 \%$ in terms of apigenin.
\end{abstract}

Keywords: dense exract; creeping thyme; BAS groups; quantitative analysis; qualitative analysis.

(C) 2020 by the authors. This article is an open-access article distributed under the terms and conditions of the Creative Commons Attribution (CC BY) license (https://creativecommons.org/licenses/by/4.0/). 


\section{Introduction}

One of the priority directions of the modern pharmaceutical industry is the development of new drugs of plant origin [1-3]. The long-known herbal medicinal products (HMP), which remain relevant for the production of drugs, is a herb of creeping thyme (CT) [3, 4]. This development involves obtaining a dense extract, so the purpose of our work is to develop technology and standardize the dense extract of creeping thyme. Pharmaceutical development of mucolytic agent with dense extract of creeping thyme and essential oil of thyme involves obtaining a dense thyme extract of creeping, that is, choosing of optimal conditions that will allow in a short time to obtain a dense extract enriched with the main biological active substances (BAS) - which is a resultant extract and finished drug. Since in the analysis of creeping thyme herb in order to standardize this raw material as a quality index, among others, we chose the composition of flavonoids and hydroxycinnamic acids and the quantitative content of flavonoids, then it is appropriate to study the qualitative and quantitative composition of these bioactive substances (BAS) and in the obtained extract [7-10].

\section{Materials and Methods}

Identification and determination of the quantitative content of the analyzed BAS in HMP and their respective extracts were carried out using modern sensitive and selective methods of analysis. The qualitative composition of flavonoids was determined by the thinlayer chromatography method $[11,12]$ in the solvent system ethyl acetate $P$ - formic acid $P$ water $P$ (90:6:9). The determined volumes of solutions were applied to chromatographic plates Silica gel F254 of company "Merck" using a device for automatic sampling on "CAMAG Linomat 5" plate, chromatography was carried out in a "GAMAG" chromatography chamber. Approaching the standardization of liquid and dense thyme creeping extract, we considered the possibility of identifying the same BAS, continuing the proposed approach in the HMP chain - extracts [9]. The determination of the amount of flavonoids was carried out by the method of differential spectrophotometry on the spectrophotometer of the brand "Cary-50" [12]. The quantitative content of flavonoids in the dense extract was determined by the reaction of the formation of the colored compound directly of flavonoids with aluminum chloride. To solve the problems a liquid extract of CT has been used, the technology of which has been described by us in the patent of Ukraine on the utility model No. 73543 [5] and the following equipment: a deep vacuum VT6 pump with a maximum dilution of up to $0.85 \mathrm{kp} / \mathrm{cm}^{2}$ with vacuum gauge ОБВ 1-300 with range measurement from 0 to $-1 \mathrm{kp} / \mathrm{cm}^{2}$; laboratory rotary evaporator LABOROTA 4001.

During the experiment, we took $500 \mathrm{ml}$ of a creeping thyme extract. Evaporation was carried out to a volume of $100 \mathrm{ml}$ fixing the time of evaporation under the following conditions: - temperature value $60{ }^{0} \mathrm{C}$, vacuum $0,6 \mathrm{kp} / \mathrm{cm}^{2}$;

- temperature value $60{ }^{\circ} \mathrm{C}$, vacuum $0,8 \mathrm{kp} / \mathrm{cm}^{2}$;

- temperature value $80{ }^{0} \mathrm{C}$, vacuum $0,6 \mathrm{kp} / \mathrm{cm}^{2}$;

- temperature value $80{ }^{0} \mathrm{C}$, vacuum $0,8 \mathrm{kp} / \mathrm{cm}^{2}$.

Modes of the inspissation of liquid extract of creeping thyme results are presented in Table 1.

Table 1. Modes of inspissation of liquid extract of creeping thyme.

\begin{tabular}{|c|c|c|c|c|}
\hline \multirow{2}{*}{ Mode } & \multicolumn{4}{|c|}{ Temperature, ${ }^{\circ} \mathrm{C}$} \\
\hline & \multicolumn{2}{|c|}{60} & \multicolumn{2}{|l|}{80} \\
\hline Vacuum, $\mathrm{kp} / \mathrm{cm}^{2}$ & 0,6 & 0,8 & 0,6 & 0,8 \\
\hline $\begin{array}{l}\text { Time of evaporation, min. } \\
\text { ( from } 500 \mathrm{ml} \text { to } 100 \mathrm{ml} \text { ) }\end{array}$ & 95 & 80 & 65 & 55 \\
\hline
\end{tabular}


From the data obtained, it can be concluded that the temperature of evaporation is essentially influenced, that it is about $50 \%$ faster, evaporate the extract at $80^{\circ} \mathrm{C}$, compared to $60^{\circ} \mathrm{C}$ of evaporation. With a vacuum dilution of $0.8 \mathrm{kp} / \mathrm{cm}^{2}$, the gain is about $15-20 \%$ in comparison with the vacuum of $0.6 \mathrm{kp} / \mathrm{cm}^{2}$.

The technological process of producing dense creeping thyme extract consists of the following stages:

Stage 1. Sanitary preparation of production.

Stage 2. Preparation of raw materials

Stage 3. Obtaining a liquid extract from a creeping thyme herb.

Stage 4. Obtaining extract of dense creeping thyme.

Sanitary preparation of production includes the following operations:

Stage 1.1. preparation of disinfectant solutions;

Stage 1.2. preparation of ventilation air;

Stage 1.3. preparation of production premises;

Stage 1.4. preparation of equipment and inventory;

Stage 1.5. preparation of workwear;

Stage 1.6. training of work personnel.

Extract of dense thyme creeping from a vacuum-evaporation devise pos. P81 is unloaded into a clean, dry polyethylene barrel. The controller of QCD of the enterprise selects a sample of finished products for analysis on compliance with the requirements of Quality Control Techniques No.UA/6809/01/01 (K4.2.7).

Identification and determination of the quantitative content of the analyzed BAS in HMP and their respective extracts were carried out using modern sensitive and selective methods of analysis. The qualitative composition of flavonoids was determined by the thinlayer chromatography method $[11,12]$ in the solvent system ethyl acetate $P$ - formic acid $P$ water $P$ (90:6:9). The determined volumes of solutions were applied to chromatographic plates Silica gel F254 of company "Merck" using a device for automatic sampling on "CAMAG Linomat 5" plate, chromatography was carried out in a "GAMAG" chromatography chamber. Approaching the standardization of liquid and dense thyme creeping extract, we considered the possibility of identifying the same BAS, continuing the proposed approach in the HMP chain - extracts [9]. As a result of conducted thin-layer chromatography studies, we propose the following method for the identification of dense extract of creeping thyme.

Method for dense identification extract of creeping thyme:

Test solution: $0.4 \mathrm{~g}$ of a dense extract of creeping thyme is dissolved in $10 \mathrm{ml}$ of $96 \%$ ethanol $\mathrm{P}$ in an ultrasonic bath for 10 minutes, filtered.

Blank solution. $0.5 \mathrm{mg}$ of RS of rosmarinic acid (Fluka), $0.5 \mathrm{mg}$ of RS of caffeic acid (Fluka), $0.5 \mathrm{mg}$ of RS of chlorogenic acid (Fluka), $1.0 \mathrm{mg}$ of PhRS of luteolin-7-O-glucoside (SPhU), $0.5 \mathrm{mg}$ of RS of rutin (Sigma) and $0.5 \mathrm{mg}$ of luteolin (Fluka) are dissolved in $20 \mathrm{ml}$ of methanol R.

On the line of the start of the chromatographic plate, $10 \mu \mathrm{l}$ of the test solution and $5 \mu \mathrm{l}$ of a blank solution are applied separately by strips of $10 \mathrm{~mm}$. The plate is placed in the chamber with a mixture of solvents formic acid anhydrous $P$-water $P$-ethyl acetate $P$ (6:9:90). When the front of the solvents passes $10 \mathrm{~cm}$ from the start line, the plate is removed from the camera.

Drying: dried in the air, and then kept at a temperature from $100^{\circ} \mathrm{C}$ to $105^{\circ} \mathrm{C}$ for 2 minutes. 
Detection: A warm plate is sprayed with a solution of $10 \mathrm{~g} / \mathrm{l}$ of the aminomethyl ether of diphenylboronic acid $P$ in methanol $P$, dried in the air. The plate is then sprayed with a solution of $50 \mathrm{~g} / \mathrm{l}$ macrogol $400 \mathrm{P}$ in methanol $P$, dried in the air for 30 minutes, and revised in UV light with a wavelength of $365 \mathrm{~nm}$.

Results: on chromatogram of blank solution should be determined (in the order of $\mathrm{R}_{\mathrm{f}}$ growth): yellow-orange fluorescence zone, corresponding to rutin $\left(\mathrm{R}_{\mathrm{f}}=0.18\right)$, blue fluorescent zone, corresponding to chlorogenic acid $\left(\mathrm{R}_{\mathrm{f}}=0.32\right)$; yellow-orange fluorescent zone corresponding to luteolin-7-O-glucoside $\left(\mathrm{R}_{\mathrm{f}}=0.42\right)$, light green-blue fluorescent zone, corresponding to rosmarinic acid $\left(\mathrm{R}_{\mathrm{f}}=0.80\right)$, blue fluorescent zone, corresponding to caffeic acid $\left(R_{f}=0,82\right)$, yellow-orange fluorescent zone, corresponding to luteolin $\left(R_{f}=0.84\right)$.

On the chromatogram of the test solution should be detected six zones (rutin, chlorogenic acid, luteolin-7-O-glucoside, rosmarinic acid, caffeic acid, and luteolin) at the level of zones on the chromatogram of blank solution corresponding to their coloring and fluorescence and the bright yellow-orange zone of fluorescence $\left(R_{f}=0.29\right)$ below the zone of chlorogenic acid on the chromatogram of blank solution. Other zones of blue and yelloworange fluorescence may be detected.

The sequence of zones on the chromatograms of test solution (dense extract) and a blank solution is shown in Picture 2 below.

Method for the identification of monosaccharides in a dense extract of creeping thyme.

Test solution: $0.4 \mathrm{~g}$ of dense extract was placed in a centrifuge tube, $10 \mathrm{ml}$ of water $P$ was added and left in an ultrasonic bath for $10 \mathrm{~min}$, and then centrifuged. The supernatant fluid was transferred to a $100-\mathrm{ml}$ glass, $30 \mathrm{ml}$ of $96 \%$ alcohol was added. The solution was then settled for 1 hour, centrifuged, decanted, and the following operations were performed with precipitate: was added $5 \mathrm{ml}$ of acid $2 \mathrm{~mol} / \mathrm{l}$ sulfate and transferred quantitatively to a $50 \mathrm{ml}$ flask with slide. Heating was conducted in a water bath under reflux for 1 hour. After the hydrolysis, the resulting solution was neutralized by carbonate barium. Later the mixture was centrifuged, the precipitate was removed, and the supernatant fluid was used as the test solution.

Blank solution: $10 \mathrm{mg}$ of standard samples of fructose, glucose, arabinose, galactose, xylose, and rhamnose were placed in a volumetric flask and dissolved in water $P$, bringing the solution volume with water $P$ to the mark.

To the starting line of the chromatographic plate, "Silica gel" with size 20 x $20 \mathrm{~cm}$ (Merck, Germany) is applied $15 \mu \mathrm{l}$ of the test solution and $5 \mu \mathrm{l}$ of blank solution. The plate is dried in air for 10 minutes, placed in a mobile phase chamber water $P$-acetonitrile $P$ (15:85), and chromatographed by an ascending method. When the front of solvents passes $15 \mathrm{~cm}$ from the start line, it is taken out of the chamber and dried in the air. The plate is sprayed with a solution of thymol $(0.5 \mathrm{~g}$ of thymol, $5 \mathrm{ml}$ of concentrated sulfuric acid, and $95 \mathrm{ml}$ of $96 \%$ of alcohol $P$ ) and heated at a temperature of $100-105^{\circ} \mathrm{C}$ for $3-5$ minutes, revised in daylight.

As a result, the presence of fructose, glucose, arabinose, xylose, and rhamnose in a dense extract of creeping thyme was established. By the ratio of the size and intensity of staining on chromatograms, it was concluded that the predominant monosaccharide is fructose, and from reconstructive monosaccharides - glucose. Thus, it is suggested that the presence of fructose and glucose should be chosen as markers of the quality of the test extract.

In order to prove the presence of amino acids in the corresponding extract, thin-layer chromatography analysis was performed [14]. 

below.

The method for identifying amino acids in a dense extract of creeping thyme is given

Test solution: $0.4 \mathrm{~g}$ of the dense extract is dissolved in $10 \mathrm{ml}$ of alcohol $(30 \%, v / v) P$ in an ultrasonic bath for 10 minutes.

Blank solution: $10 \mathrm{mg}$ of standard samples of glycine, leucine, tyrosine, alanine, aspartic acid, and glutamic acid are dissolved in $25 \mathrm{ml}$ of water $P$.

On the starting line of chromatographic plate Silica gel $F_{254}$ with size, $20 \times 20 \mathrm{~cm}$ with a thickness of $0.25 \mathrm{~mm}$ is applied with strips of $10 \mathrm{~mm}$ in length $20 \mu \mathrm{l}$ of the test solution and 5 $\mu \mathrm{l}$ of blank solution. The plate is dried in the air for $30 \mathrm{~min}$, placed in a mobile phase chamber with isopropanol $P$ - formic acid $P$ - water $P$ (40: 2: 10) and chromatographed by ascending method. When the front of solvents passes $15 \mathrm{~cm}$ from the start line, it is taken out of the chamber and dried in the air. The plate is sprayed with a solution of ninhydrin $P$ in a mixture of acetic acid $P$ and butanol $P$, heated at a temperature of $100-105^{\circ} \mathrm{C}$ for $3-5$ minutes and viewed in daylight.

On the chromatograms of the tested solution of dense extract, zones of tyrosine, alanine, leucine, glycine, glutamine, and aspartic acids were observed at the level of corresponding zones on the chromatogram of comparison solution.

The next stage of the study was the identification of polysaccharides in a dense extract of creeping thyme and performance using the thin-layer chromatography method on the plates "Silica gel" (Merck, Germany) in the solvent system water P-acetonitrile P (15:85) using a solution of RS of monosaccharides (arabinose, galactose, rhamnose, fructose, glucose, xylose). Chromatograms were indicated by the solution of thymol ( $0.5 \mathrm{~g}$ of thymol, $5 \mathrm{ml}$ of concentrated sulfuric acid, and $95 \mathrm{ml}$ of $96 \%$ ethyl alcohol).

The determination of the amount of flavonoids was carried out by the method of differential spectrophotometry on the spectrophotometer of the brand "Cary-50" [12].

Since apigenin was selected as the standard for calculating their content in raw materials, then when controlling the quality of extracts, it is necessary to calculate the number of flavonoids on apigenin [9].

Differential electronic absorption spectra of a complex of aluminum chloride with flavonoids, present in the dense extract of creeping thyme, are characterized by the presence of a maximum of absorption at $390 \pm 2 \mathrm{~nm}$ (Fig. 1).

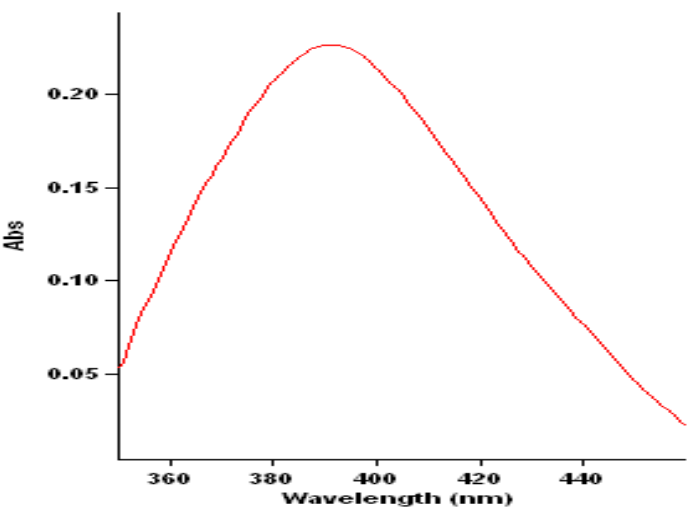

a)

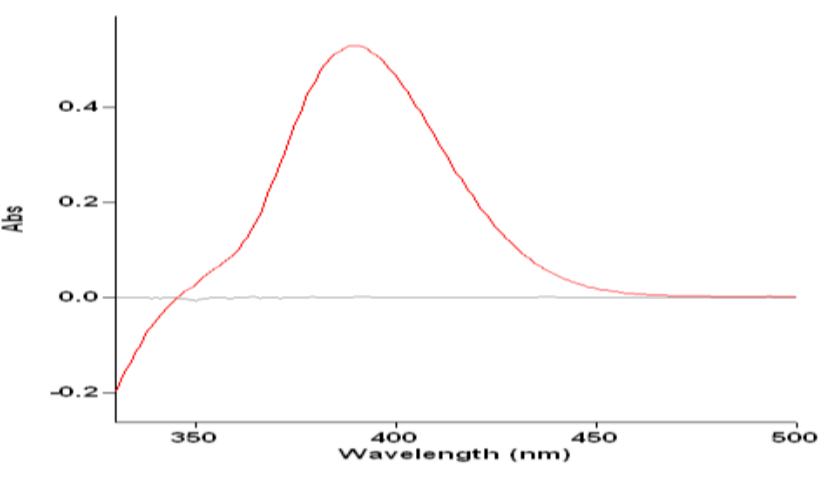

b)

Figure. 1. Differential electronic absorption spectra of test (a) and blank solution (b) under the quantitative determination of flavonoids in a dense extract of creeping thyme $\left(\lambda_{\max }=390,0 \mathrm{~nm}\right)$.

As can be seen, in terms of quantitative determination of flavonoids, the absorption spectrum of test solution for the studied dense extract of creeping thyme along the course of the curve and the position of maximum corresponds to the absorption spectrum of the 
corresponding complex of apigenin. Therefore the amount of flavonoids in the extract was calculated in terms of apigenin.

We propose the following procedure to determine the amount of flavonoids in a dense extract of creeping thyme.

Method for determining the amount of flavonoids in a dense extract of creeping thyme.

Initial solution: $0.13 \mathrm{~g}$ (exact sample weight) of a dense extract of creeping thyme is placed in a $25 \mathrm{ml}$ volumetric flask, dissolved in $20 \mathrm{ml}$ of alcohol $(60 \%, v / v) P$, and the volume of solution is adjusted to the mark with the same alcohol, then mixed.

Test solution: $1.0 \mathrm{ml}$ of initial solution is placed in a $25 \mathrm{ml}$ volumetric flask, $2.0 \mathrm{ml}$ of $3 \%$ solution of aluminum chloride is added and adjusted with alcohol $(70 \%, v / v) P$ to the mark, then mixed.

Compensation solution: $1.0 \mathrm{ml}$ of initial solution is placed in a $25 \mathrm{ml}$ volumetric flask, and the volume of solution is adjusted with alcohol $(70 \%, v / v) P$ to the mark, then mixed.

Standard solution of apigenin: 0,03 g (exact sample weight) of a standard sample of apigenin (Fluka) is placed in a $100 \mathrm{ml}$ volumetric flask, $70 \mathrm{ml}$ of alcohol $(70 \%, v / v)$ of $P$ is added, dissolved, and the volume of solution is adjusted to the mark with the same solvent and then mixed.

$10.0 \mathrm{ml}$ of the resulting solution is placed in a $25 \mathrm{ml}$ volumetric flask, and the volume of solution is adjusted with alcohol $(70 \%, v / v) P$ to the mark, then mixed.

Blank solution: $1.0 \mathrm{ml}$ of a solution of a standard sample of apigenin is placed in a 25 $\mathrm{ml}$ volumetric flask, $2.0 \mathrm{ml}$ of $3 \%$ aluminum chloride solution is added, and the volume of solution is adjusted with alcohol $(70 \%, v / v) P$ to the mark, then mixed.

Compensation solution: $1.0 \mathrm{ml}$ of a solution of a standard sample of apigenin is placed in a $25 \mathrm{ml}$ volumetric flask, and the volume of solution is adjusted with alcohol $(70 \%, v / v) P$ to the mark, then mixed.

After 45 minutes, differential electronic absorption spectra are recorded for the test solution and blank solution relative to compensation solutions for each, respectively, and the optical density is measured at the absorption maximum at a wavelength of $390 \pm 2 \mathrm{~nm}$.

Method of quantitative determination of the content of reconstructive monosaccharides in a dense extract of creeping thyme.

Initial solution: $0.2 \mathrm{~g}$ (exact sample weight) of a dense extract of creeping thyme is placed in a $25 \mathrm{ml}$ volumetric flask, added $10 \mathrm{ml}$ of water $P$, dissolved and placed in a centrifuge tube of $50 \mathrm{ml}$ capacity, added $30 \mathrm{ml}$ of $96 \%$ alcohol $P$, mixed and heated in a water bath at a temperature of $30^{\circ} \mathrm{C}$ for 5 minutes. Maintained for 1 hour, the content is centrifuged, the supernatant fluid is discarded, and the precipitate is transferred with $5.0 \mathrm{ml}$ of acid of diluted hydrochloric $\mathrm{P}$ and $5.0 \mathrm{ml}$ of water $\mathrm{P}$ in a conical flask of $50 \mathrm{ml}$ capacity with slide and heated for 1 hour with a reflux condenser in boiling water bath. Flask with content is cooled, placed a small piece of congo paper in a flask and added $40 \%$ sodium hydroxide solution to reddening the paper drop by drop, then added drops of hydrochloric acid diluted to the paper, and then drop by drop $10 \%$ sodium hydroxide solution until the paper reddened. The resulting solution is transferred quantitatively with water $\mathrm{P}$ into a volumetric flask of $25 \mathrm{ml}$ capacity, brought the volume of solution to the mark with water $\mathrm{P}$, mixed and filtered, discarding the first $5 \mathrm{ml}$ of filtrate.

Test solution: $1.0 \mathrm{ml}$ of $1 \%$ citric acid solution is placed in a $25 \mathrm{ml}$ flat bottom flask, added $3.0 \mathrm{ml}$ of $20 \%$ solution of sodium carbonate, and $1.0 \mathrm{ml}$ of solution B. The flask with content is kept in a boiling water bath for 10 minutes, then cooled to room temperature. The 
content of the flask is transferred quantitatively with water $P$ into a volumetric flask of $25 \mathrm{ml}$ capacity and brought the volume of solution to the mark with water $P$.

Standard sample of glucose: $0.14 \mathrm{~g}$ (exact sample weight) of a standard sample of glucose (Fluka), dried at a temperature of 100 to $105^{\circ} \mathrm{C}$ to a constant mass, is placed in a volumetric flask of $100 \mathrm{ml}$ capacity, dissolved in $50 \mathrm{ml}$ of water $P$, adjusted the volume of solution with water $P$ to the mark and mixed. $10,0 \mathrm{ml}$ of the resulting solution is placed in a 25 $\mathrm{ml}$ volumetric flask, adjusted the volume of solution with water $P$ to the mark, and mixed.

Blank solution: $1.0 \mathrm{ml}$ of $1 \%$ picric acid solution, $3.0 \mathrm{ml}$ of $20 \%$ solution of sodium carbonate, and $1.0 \mathrm{ml}$ of a solution of standard glucose sample, treated similarly to the test solution, starting with the words: "The flask with contents is adjusted...".

Compensation solution: $1.0 \mathrm{ml}$ of $1 \%$ picric acid solution, $3.0 \mathrm{ml}$ of $20 \%$ sodium carbonate solution, and $1,0 \mathrm{ml}$ of water $P$, treated similarly to the test solution, starting with the words: "The flask with contents is adjusted ...".

The optical density of the test solution and a blank solution is measured at a wavelength of $460 \mathrm{~nm}$ relative to the compensation solution.

Method of quantitative determination of the content of amino acids in a dense extract of creeping thyme.

Test solution: $0.13 \mathrm{~g}$ (exact sample weight) of a dense extract of creeping thyme is placed in a $25 \mathrm{ml}$ volumetric flask, dissolved in $20 \mathrm{ml}$ of alcohol $(30 \%, \mathrm{v} / \mathrm{v})$, and brought the solution volume to the mark with the same alcohol, then mixed.

$1.0 \mathrm{ml}$ of the resulting solution is treated in a similar manner to the test solution placed in the test tube, $1,1 \mathrm{ml}$ of freshly prepared $0,2 \%$ ninhydrin solution $P$ is added, and heated in a boiling water bath for 20 minutes. After complete cooling, transferred the solution quantitatively into a volumetric flask of $100 \mathrm{ml}$ capacity and diluted with water $\mathrm{P}$ to the mark, mixed.

Blank solution: $0.059 \mathrm{~g}$ (exact sample weight) $\mathrm{PhRS}$ glycine is placed in a volumetric flask of $100 \mathrm{ml}$ capacity, $70 \mathrm{ml}$ of water $P$ is added, dissolved for 5-10 minutes, heated in a water bath at a temperature of $50{ }^{\circ} \mathrm{C}$. Cooled and brought the volume of solution with water $P$ to $100 \mathrm{ml}$ and mixed.

To $1.0 \mathrm{ml}$ of received solution, placed in the test tube, is added $1.1 \mathrm{ml}$ of $0.2 \%$ solution of ninhydrin $P$ and heated in a boiling water bath for 20 minutes. After complete cooling, the solution is transferred quantitatively into a volumetric flask of $100 \mathrm{ml}$ capacity and diluted with water $P$ to the mark, mixed.

Compensation solution: $1.0 \mathrm{ml}$ of water $P$ is placed in the test tube, is added $1.1 \mathrm{ml}$ of $0.2 \%$ solution of ninhydrin $P$, and heated in a boiling water bath for 20 minutes. After complete cooling, the solution is transferred quantitatively into a volumetric flask of $100 \mathrm{ml}$ capacity and diluted with water $P$ to the mark, mixed.

0,2\% solution of ninhydrin P: $0.1 \mathrm{~g}$ of ninhydrin is placed in a $50 \mathrm{ml}$ volumetric flask, dissolved in $30 \mathrm{ml}$ of water $P$, the volume of solution is adjusted to the mark with the same solvent and mixed.

After 1 hour, the optical density of the test solution and blank solution on a spectrophotometer at a wavelength of $567 \pm 2 \mathrm{~nm}$ in a cuvette with a thickness of $10 \mathrm{~mm}$ relative to the compensation solution is measured. 


\section{Results and Discussion}

The result, the finished product was received - a dense extract of creeping thyme herb, which is a dense bundle of mass that does not pour out of the container but extends into the filaments and once again fuses into a solid mass with a specific odor. Chromatographic studies of a dense extract of creeping thyme by the thin-layer chromatography method have allowed identifying phenol carboxylic acids - rosmarinic (main representative), caffeic and chlorogenic; flavonoids - luteolin-7-O-glucoside, apigenin-7-O-glucoside, luteolin, apigenin, and rutin. Two acids were not identified, small quantities of which are found in the upper part of a chromatogram and of the unidentified structure of luteolin glucoside, which, by size and intensity of fluorescence, are not the main representative of flavonoids in the extract. Based on the literature [13], this representative of flavonoids may be luteolin-7-O-di or triglycoside.

As a result of conducted thin-layer chromatography studies (Fig. 2), the presence of flavonoids and phenol carboxylic acids in a dense extract of creeping thyme has been proved, which would allow to objectively establish the identity of investigated extracts for the presence of BAS of used raw material.

Upper part of the plate
\begin{tabular}{l|l} 
Luteolin: yellow-orange fluorescent area \\
Caffeic acid: blue fluorescence zone \\
$\begin{array}{l}\text { Rosmarinic acid: light green-blue fluorescence zone } \\
\text { Luteolin-7-O-glucoside: yellow-orange fluorescence zone }\end{array}$ & $\begin{array}{l}\text { yellow-orange fluorescent area (luteolin) } \\
\text { blue fluorescence zone (caffeic acid) } \\
\text { light green-blue fluorescence zone (rosmarinic acid) } \\
\text { yellow-orange fluorescence zone (luteolin-7-O-glucoside) }\end{array}$ \\
Chlorogenic acid: blue fluorescent zone & $\begin{array}{l}\text { blue fluorescent zone (chlorogenic acid) } \\
\text { very intense yellow-orange fluorescence zone }\end{array}$ \\
Rutin: yellow-orange fluorescent area & yellow-orange fluorescent area (rutin) \\
\hline Test solution & Blank solution
\end{tabular}

Figure 2. Scheme of the chromatogram in conditions of identification of dense extract of creeping thyme after treatment with solutions of an amine-ethyl ester of diphenylboronic acid and macrogol 400 when viewed in UV light with a wavelength of $365 \mathrm{~nm}$.

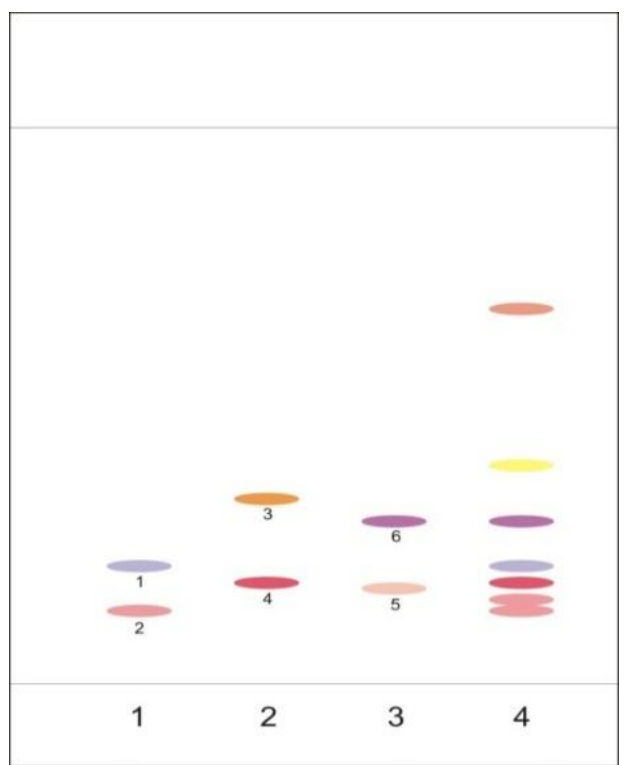

Figure 3. Scheme of the chromatogram of a dense extract of creeping thyme (4) and blank solutions (1, 2, 3, where 1 - arabinose, 2 -galactose, 3 - rhamnose, 4 - fructose, 5 -glucose, 6 -xylose) in the conditions of identification of monosaccharides 
As a result of the chromatographic study (Fig. 3), we identified seven monosaccharides, one of which remained unknown due to the lack of a required standard.

The scheme of the chromatogram obtained during the study of a dense extract of creeping thyme in terms of the identification of amino acids is shown in Figure 4.

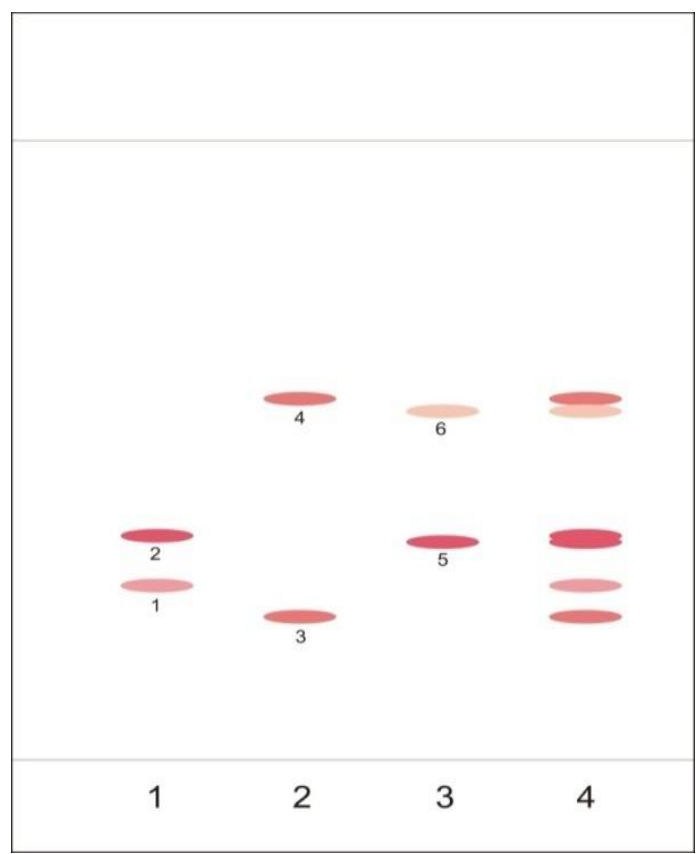

Figure 4. Scheme of the chromatogram of the test solution (4) and blank solutions $(1,2,3)$, in which $1-$ glycine; 2 - alanine; 3 - aspartic acid; 4 - leucine; 5 - glutamic acid; 6 -tyrosine.

Results of the quantitative determination of the amount of flavonoids in the dense extract are given in Table 2.

Table 2. Results of determination the content of flavonoids in dense extract $(P=0.95, n=5)$.

\begin{tabular}{|c|c|c|c|c|}
\hline \multirow{2}{*}{ 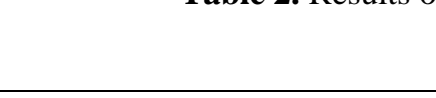 } & \multicolumn{4}{|c|}{ Content of flavonoids in terms of apigenin, $\%$} \\
\hline & No.1 & No.2 & No.3 & No.4 \\
\hline Dense extract of creeping thyme & $2.81 \pm 0.01$ & $2.80 \pm 0.02$ & $2.81 \pm 0.03$ & $2.77 \pm 0.02$ \\
\hline
\end{tabular}

Given the results of quantitative determination, standardizing the dense extract can be proposed as a quality criterion for the content of flavonoids-not less than $2,5 \%$ in terms of apigenin [9-12].

The quantitative content of reconstructive monosaccharides (Table 3) in the investigated extract varies and is determined by the content in the raw material and the reproducibility of the selected extract technology.

Table 3. Results of determination of the content of reconstructive monosaccharides in a dense extract of creeping thyme $(\mathrm{P}=0,95, \mathrm{n}=5)$.

\begin{tabular}{l|l|l|l|l}
\multirow{2}{*}{ Extract } & \multicolumn{3}{|l}{ Content of reconstructive monosaccharides in terms of glucose, \% } \\
\cline { 2 - 5 } & No.1 & No.2 & No.3 & No.4 \\
\hline Dense extract of creeping thyme & $6.02 \pm 0.10$ & $6.87 \pm 0.09$ & $5.60 \pm 0.10$ & $6.97 \pm 0.11$
\end{tabular}

Determination of amino acids in the obtained extract of creeping thyme was also performed by spectrophotometry in the visible spectral region using the well-known and used photometric reaction of the formation of a colored compound of amino acids with ninhydrin (Table 4) [14-16]. 
Table 4. Results of quantitative determination of the amount of amino acids in dense extract of creeping thyme $(\mathrm{P}=0,95, \mathrm{n}=5)$.

\begin{tabular}{l|l|l|l|l}
\multirow{2}{*}{ Extract } & \multicolumn{4}{|l}{ Content of amino acids in terms of glycine, \% } \\
\cline { 2 - 5 } & No.1 & No.2 & No.3 & No.4 \\
\hline Dense extract of creeping thyme & $1.86 \pm 0.02$ & $2,18 \pm 0.01$ & $1,50 \pm 0.01$ & $2,08 \pm 0.02$
\end{tabular}

Therefore, acids - rosmarinic, caffeic, chlorogenic and flavonoids - luteolin-7-Oglucoside, rutin, and luteolin, as well as the unidentified composition of luteolin glucoside, as the identity markers of a dense extract of creeping thyme, the presence of which zones on the chromatogram of the investigated object will allow it to be objectively identified [11].

The quantity of flavonoids in the investigated extract varies within certain limits and is determined by their content in the raw material and the reproducibility of extract technology. Given the results of quantitative determination, standardizing the dense extract can be proposed as a quality criterion for the content of flavonoids-not less than 2,5\% in terms of apigenin [9-12]. The quantity of flavonoids in the investigated extract varies within certain limits and is determined by their content in the raw material and the reproducibility of extract technology.

Guided by the results of the quantitative determination of reconstructive monosaccharides, when standardizing the dense extract of creeping thyme, the quality of the content of reconstructive monosaccharides can be proposed to be at least $5.0 \%$ in terms of glucose.

Thus, the quantitative content of the amount of amino acids in terms of glycine in the studied extract of creeping thyme has been determined as a quantitative quality criterion has been proposed their content of at least $1,0 \%$ in the dense extract, respectively.

\section{Conclusions}

The qualitative composition of a dense extract of creeping thyme herb in BAS groups - flavonoids, amino acids, polysaccharides has been studied. In order to standardize the extract, identification markers from phenolic compounds - luteolin-7-O-glucoside, luteolin, rutin, chlorogenic, rosmarinic, and caffeic acids, luteolin glycoside of unknown composition has been proposed. The quantitative content of flavonoids, amino acids, and reconstructive monosaccharides in the dense extract has been investigated. The correlation of content of the main BAS groups for dense extract indicates that the selected conditions for transferring the liquid extract to the dense are correct. When standardizing the dense extract of creeping thyme by the flavonoid content is proposed to be at least $2.5 \%$ in terms of apigenin.

\section{Funding}

This research received no external funding.

\section{Acknowledgments}

This research has no acknowledgment.

\section{Conflicts of Interest}

The authors declare no conflict of interest. 


\section{References}

1. European Pharmacopoeia. European Pharmacopoeia. $10 \quad$ edn. https://www.edqm.eu/en/european_pharmacopoeia_10th_edition

2. The State Pharmacopeia of Ukraine in 3 vol. State Enterprise Ukrainian Scientific Expert Pharmacopoeial Center of the Quality of Medicines. 2nd iss. Kharkiv: State Enterprise "Ukrainian Scientific and Experimental Pharmacopoeial Center for the Quality of Medicinal Products" 1128, 2015.

3. Karamad, D.; Khosravi-Darani, K.; Hosseini, H.; Tavasoli S. Analytical procedures and methods validation for oxalate content estimation. Biointerface Research in Applied Chemistry 2019, 9, https://doi.org/10.33263/BRIAC95.305310.

4. Goswami, A.; Jiang, J.Q. Simultaneous quantification of gabapentin, sulfamethoxazole, terbutryn, terbuthylazine and diuron by uv-vis spectrophotometer. Biointerface Research in Applied Chemistry 2018, 8, 3111-3117.

5. Logoyda, L. Analysis of approaches to the development and validation of the methods of analysis of some active pharmaceutical ingredients from the group of calcium channel blockers in drugs and biological liquids. International Journal of Applied Pharmaceutics 2019, 11, 26-34, https://doi.org/10.22159/ijap.2019v11i3.32498.

6. Logoyda, L.; Abdel-Megied, A.M.; Kondratova, Y.; Trofimenko, O.; Korobko, D.; Dakhym, I. Development and validation of HPLC method for the simultaneous determination of enalapril maleate in present of their impurities: application to tablet analysis. International Journal of Applied Pharmaceutics 2018, 10, 98-102, https://doi.org/10.22159/ijap.2018v10i1.22805.

7. Logoyda, L. Dmytro, K.; Oleksandra, O.; Taras, P.; Mariya, D. A HPLC-MS/MS method development and validation for the simultaneous determination of bisoprolol and enalapril in the present of enalaprilat in human plasma. International Journal of Applied Pharmaceutics 2018, 10, 31-40, https://doi.org/10.22159/ijap.2018v10i2.23195.

8. Kondratova, Y.; Adebayo, T.; Logoyda, L.; Korobko, D.; Berdey, I.; Kuchmerovska, T. Development of the methodology of the chromatographic determination of amlodipine in medicines. Int. J. Res. Ayurveda Pharm. 2016, 7, 32-35, https://doi.org/10.7897/2277-4343.074128.

9. Kondratova, Y.; Logoyda, L.; Voloshko, Y.; Abdel-Megied, A.; Korobko, D.; Soroka, Y. Development and validation of HPLC-DAD method for the determination of bisoprolol in tablet dosage forms. Int J App Pharm. 2017, 9, 54-9, https://doi.org/10.22159/ijap.2017v9i6.21616.

10. Polyauk, O.; Logoyda, L. The investigation of conditions of API from group of calcium channel blockers extraction by organic solvents by using high-performance liquid chromatography as method assay. Asian $J$ Pharm Clinical Res. 2017, 10, 354-356.

11. Yuryeva, O.; Kondratova, Y.; Logoyda, L. Development of high-performance liquid chromatography method for simultaneous analysis of amlodipine and valsartan in combined dosage form and in vitro disslotution studies. Asian Journal of Pharmaceutical and Clinical Research. 2018, 11, 200-204, https://doi.org/10.22159/ajpcr.2018.v11i5.24443.

12. Logoyda, L. A high-performance liquid chromatography-mass spectrometry method development for the quantitative determination of enalapril maleate from Caco-2 cell monolayers. Asian Journal of Pharmaceutical and Clinical Research 2018, 11, 89-92, https://doi.org/10.22159/ajpcr.2018.v11i7.25455.

13. Logoyda, L.; Korobko, D. A high-performance liquid chromatography-mass spectrometry/mass spectrometry method development for the quantitative determination of bisoprolol from Caco-2 cell monolayers. Asian Journal of Pharmaceutical and Clinical Research 2018, 11, 386-389, https://doi.org/10.22159/ajpcr.2018.v11i4.24990.

14. Logoyda, L. A HPLC-MS/MS method development and validation for the simultaneous determination of nifedipine and enalapril in human plasma. International Journal of Applied Pharmaceutics 2018, 10, 35-42, https://doi.org/10.22159/ijap.2018v10i4.24528.

15. Chidambaram, S.; Thenrajan, R.; Benedict Lydia, Pillappan Ramkumar. Formulation and evaluation of Prednisolone retention enema as dispersible tablet and vehicle for the treatment of ulcerative colitis. Letter in Applied NanoBioScience 2019, 8, 545-552, https://doi.org/10.33263/LIANBS82.545552.

16. Rania, B.; Sherif, E.; Hanan, E.; Nadra, N.; Medhat, I. On the molecular modeling analyses of sodium carboxymethyl cellulose treated with acetic acid. Letter in Applied NanoBioScience 2019, 8, 553-557. https://doi.org/10.33263/LIANBS82.553557. 